\section{Landmark Report Analyzes Current State of U.S. Offshore Wind Industry}

New report assesses offshore wind technology challenges and potential risks and benefits.

The National Renewable Energy Laboratory (NREL) recently published a new report that analyzes the current state of the offshore wind energy industry, Large-Scale Offshore Wind Power in the United States. It provides a broad understanding of the offshore wind resource, and details the associated technology challenges, economics, permitting procedures, and potential risks and benefits of developing this clean, domestic, renewable resource.

The United States possesses large and accessible offshore wind energy resources. The availability of these strong offshore winds close to major U.S. coastal cities significantly reduces power transmission issues.

The report estimates that U.S. offshore winds have a gross potential generating capacity four times greater than the nation's present electric capacity.

According to the report, developing the offshore wind resource along U.S. coastlines and in the Great Lakes would help the nation:

- Achieve $\mathbf{2 0 \%}$ of its electricity from wind by $\mathbf{2 0 3 0}$ - Offshore wind could supply 54 gigawatts of wind capacity to the nation's electrical grid, increasing energy security, reducing air and water pollution, and stimulating the domestic economy.

- Provide clean power to its coastal demand centers - Wind power emits no carbon dioxide (CO2) and there are plentiful winds off the coasts of 26 states.

- Revitalize its manufacturing sector - Building 54 GW of offshore wind energy facilities would generate an estimated $\$ 200$ billion in new economic activity, and create more than 43,000 permanent, well-paid technical jobs in manufacturing, construction, engineering, operations and maintenance.

NREL's report concludes that the development of the nation's offshore wind resources can provide many potential benefits, and with effective research, policies, and commitment, offshore wind energy can play a vital role in future U.S. energy markets.

Technical Contact: Walt Musial, walter.musial@nrel.gov

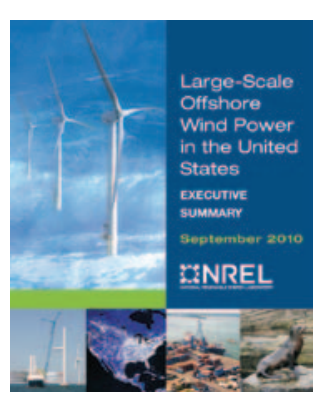

http://www.nrel.gov/docs/ fy10osti/49229.pdf

\section{Key Research Results}

Achievement

The United States is now deliberating an energy policy that could have a powerful impact on the nation's energy and economic health for decades to come. This report provides a broad understanding of today's offshore wind industry, as well as the associated technology challenges, resource, economics, permitting procedures, and potential risks and benefits. An appreciation for all sides of these issues will help to build an informed national dialog and shape effective national policies.

Key Result

Accelerating the deployment of offshore wind could have tremendous benefits to the United States. Technological needs are generally focused on making offshore wind technology economically feasible and reliable and expanding the technology options to accommodate a broader, more regionally diversified deployment portfolio for future U.S. offshore projects.

Potential Impact

"Wind power isn't the silver bullet that will solve all our energy challenges - there isn't one. But it is a key part of a comprehensive strategy to move us from an economy that runs on fossil fuels to one that relies on more homegrown fuels and clean energy." President Barack Obama, April 2010.

Although offshore wind alone cannot solve the nation's energy problems, this report concludes that with effective research, policies, and commitment, it can play a significant and vital role in future U.S. energy markets. Along with energy conservation and efficiency initiatives, offshore wind should be considered an essential part of a diverse sustainable energy portfolio.

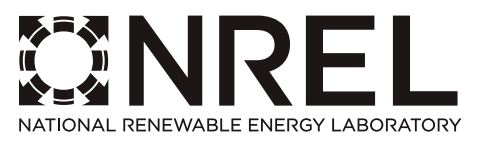

1617 Cole Boulevard | Golden, Colorado 80401-3305 | 303-275-3000 | www.nrel.gov

NREL is a national laboratory of the U.S. Department of Energy, Office of Energy Efficiency and Renewable Energy, operated by the Alliance for Sustainable Energy, LLC.

NREL/FS-5000-52664 • September 2011 